\title{
Kredibilitas Komunikator Dalam Menyampaikan Pesan (Analisis Opini Generasi Milenial Pada Kepala Penerangan Kodam Jaya)
}

\author{
Silvia, Sinta Paramita \\ laurenciasilvia@gmail.com,sintap@fikom.untar.ac.id \\ Fakultas Ilmu Komunikasi Universitas Tarumanagara
}

\begin{abstract}
This study discusses the credibility of communicators by using millennial millennial public opinion analysis at the Head of Information Kodam Jaya or Kapendam Jaya. This research uses concepts consisting of retrorics, public opinion, Strauss and Howe's generation theory and communicator credibility (source, extrinsic and intrinsic, this study uses a mixed method approach or mixed method with an explaratory sequential approach. Mix between qualitative and quantitative initial data. Qualitative data obtained from the interviews of Kapendam Jaya / Jayakarta Quantitative obtained by the authors of the survey regarding the credibility of Kapendam Jaya / Jayakarta in delivering messages or information to the millennial generation (students of Tarumangara University, Paramadina University, and Christian University of Indonesia). in the form of non-verbal communication such as uniforms is the thing most remembered by student respondents who came to attend the event or seminar, with Kapendam Jaya as the speaker.
\end{abstract}

Keywords: Public Opinion, Millennial Generation, Public Communication, Credibility

\begin{abstract}
Abstrak
Penelitian ini membahas tentang kredibilitas komunikator dengan menggunakan analisis opini publik generasi milenial pada Kepala Penerangan Kodam Jaya atau Kapendam Jaya. Penelitian ini menggunakan konsep yang terdiri retorika, opini publik, teori generasi Strauss dan Howe dan kredibilitas komunikator (sumber, ekstrinsik dan intrinsic). Penelitian ini menggunakan pendekatan mix method atau metode campuran dengan pendekatan sekuensial eksplaratori. Campuran antara data awal kualitatif dan kuantitatif. Data kualitatif diperoleh dari hasil wawancara Kapendam Jaya/Jayakarta kuantitatif diperoleh penulis dari survei mengenai kredibilitas Kapendam Jaya/Jayakarta dalam menyampaikan pesan atau informasi pada generasi milenial (mahasiswa Universitas Tarumangara, Universitas Paramadina, dan Universitas Kristen Indonesia). Temuan menarik dari penelitian ini adalah, menunjukan penampilan berupa komunikasi non verbal seperti seragam merupakan hal yang paling dingat oleh responden mahasiswa yang datang menghadiri event atau seminar, dengan Kapendam Jaya sebagai pembicaranya.
\end{abstract}

Kata Kunci: Opini Publik, Generasi Milenial, Komunikasi Publik, Kredibilitas

\section{Pendahuluan}

Sebelum era reformasi 1998, kebebasan merupakan titik terendah dari opini publik di Indonesia karena sangat dibatasi oleh pemerintahan pada saat itu. Pembungkaman opini rakyat tersebut mengacu kepada kondisi politik yang kurang stabil. Demo besar-besaran dilakukan oleh mahasiswa, salah satu tuntutannya adalah menggulingkan Presiden Soeharto. Setelah tergulingnya Presiden Soeharto era baru dimulai, yaitu era keterbukaan informasi. 
Mulainya era keterbukaan informasi tidak luput juga dari peran teknologi informasi. Menurut Candraningrum (2018), di era digital seperti sekarang, media sosial memang menjadi pilihan utama bagimasyarakat dalam mendapatkan informasi. Hal tersebut yang membuat penyebaran informasi secara cepat, dan membuat informasi menjadi lebih mudah didapatkan. Secara tidak disengaja era teknologi informasi atau yang biasa disebut dengan globalisasi menghadirkan generasi baru. Generasi baru tersebut adalah generasi milenial atau generasi Y yang lahir tahun 1982-2005. Menurut Lyons yang dikutip dari Yanuar (2017) generasi ini banyak menggunakan teknologi komunikasi instan seperti email, SMS, instant messaging dan media sosial seperti facebook dan twitter, dengan kata lain generasi Y adalah generasi yang tumbuh pada era internet booming.

Kemudahan mendapatkan informasi dari media massa terkait pemberitaan membuat banyaknya opini publik, khususnya pemberitaan terkait dengan TNI (Tentara Nasional Indonesia). Akhir tahun 2004, Indonesia diterpa bencana yang cukup dasyat, gempa bumi dan tsunami yang menimpa Nangroe Aceh Darusallam, dengan banyaknya pemberitaan yang terjadi TNI secara sigap turut membantu masyarakat dalam mengevakuasi serta membangun fasilitas penguangsian yang sangat dibutuhkan pada waktu itu (dikutip dari: https://tni.mil.id).

Seiring dengan pemberitaan media massa terhadap kinerja TNI, opini publik terhadap TNI sudah berangsur membaik, TNI sadar akan pentingnya dukungan publik terhadap eksistensi suatu lembaga. Menurut Rumantini (2005) jika opini publik muncul karena adanya kepercayaan yang kuat terhadap organisasi, hal tersebut tentunya akan memberi kepercayaan yang baik terhadap organisasi sehingga akhirnya dapat memberikan keuntungan bagi semua pihak.

Berdasarkan survei yang dilakukan oleh Charta Politica, TNI merupakan lembaga yang paling dipercaya oleh publik, yaitu sebesar $73.4 \%$ (dikutip dari: www.liputan6.com). Berdasarkan hasil survei tersebut, sebagai lembaga yang dipercaya untuk mencegah ancaman yang kemungkinan datang secara internal di masa mendatang, maka TNI menentukan salah satu target utamanya yakni, generasi muda. Generasi muda Indonesia tidak terlepas dari tuntutan dan tantangan tugas kedepan yang tidak semakin ringan, bahwa pada saat ini dan kedepan ancaman bangsa Indonesia sudah memasuki semua aspek kehidupan berbangsa dan bernegara. TNI memegang andil penting untuk mempersiapkan generasi muda (dikutip dari: http://indonews.id).

Komposisi penduduk Indonesia, 90 juta millenial (20-34 tahun), dengan total fertility rate (angka kelahiran) 2,28 (per 1.000 orang per tahun), dan angka kematian anak 24 (per 1.000 kelahiran), meski angka harapan lama sekolah masih 12,72 tahun. Artinya, generasi millenial seharusnya memiliki peran penting untuk masa depan negeri ini. Wajah masa depan Indonesia tergantung dari visi, interaksi, dan nilai-nilai yang diserap generasi millenial negeri ini. Faktanya, generasi millenial negeri ini masih rentan dengan pertarungan hoaks dan pelintiran kebencian. Terlebih lagi, medan kontestasi di media sosial turut mempengaruhi persepsi generasi millenial dalam membangun cara pandang serta melihat masa depan negeri ini. (dikutip dari: https://nasional.kompas.com)

Berdasarkan data diatas, maka sudah menjadi tugas utama TNI dalam membina generasi muda Indonesia. TNI pada tingkat Kodam yang bertugas langsung dalam mempersiapkan generasi muda ialah Penerangan Kodam (Pendam). Pendam sebagai pengemban fungsi Penerangan merupakan ujung tombak dalam perang informasi. Pendam memiliki salah satu tugas untuk melakukan penerangan Umum. Tugas yang 
dilakukan yakni terkait penyelenggaraan segala usaha, pekerjaan dan kegiatan perencanaan, persiapan, pelaksanaan, pengawasan dan pengendalian penyebaran informasi berupa fakta atau realita tentang Angkatan Darat di wilayah Kodam ke masyarakat (dikutip dari: http://www.kodam5-brawijaya.mil.id)

\section{Metode Penelitian}

Penelitian yang dilakukan oleh penulis menggunakan pendekatan kombinasi data penelitian (mixed methods). Seperti dikemukakan oleh Creswell (dalam Sugiyono, 2011) bahwa metode penelitian kombinasi merupakan pendekatan dalam penelitian yang mengkombinasikan atau menghubungkan antara metode penelitian kuantitatif dan kualitatif. Creswell (2016) membagi tiga rancangan metode campuran dasar (three basic mixed method design), yaitu model campuran pararel konvergen, metode campuran sekuensial eksplanatori, dan metode sekuensial eksloratori. Pada penelitian ini, maka penulis memilih untuk menggunakan metode penelitian metode sekuensial eksloratori. Pendekatan campuran sekuensial eksplaratori. Langkah pertama dalam metode ini adalah deskripsi rancangan, tahapan tersebut tidak termasuk pada gambar tahapan penelitian metode campuran sekuensial eskloratori karena seorang peneliti harus menentukan tujuan awal apa yang ingin diteliti.

Dalam penelitian ini, populasi penulis adalah mahasiswa Universitas Tarumanagara, Universitas Paramadina, dan Universitas Kristen Indonesia. Penulis menentukan populasi tersebut karena, sesuai dengan judul penelitian penulis dan telah mewakili generasi milenial sebagai audience. Dalam penelitian ini, peneliti menetapkan jumlah sampel sebanyak 150 orang responden, dengan kriteria sampel bahwa responden telah mengikuti seminar atau dengan pembicara Kapendam Jaya, dan peneliti menggunakan nonprobability sampling adalah teknik pengambilan sampel yang tidak memberi peluang yang sama bagi setiap unsur (anggota) populasi untuk dipilih menjadi anggota sampel. Jenis teknik nonprobability sampling yang digunakan adalah purposive sampling. Purposive sampling adalah teknik penentuan sampel dengan pertimbangan tertentu (Sugiyono, dalam Fitriyani 2016:57). Alasan peneliti memilih sampel dengan menggunakan pendekatan purposive sampling adalah karena tidak semua sampel menghadiri event / seminar, peserta dalam seminar yang dihadiri oleh generasi milenial, yang diadkan oleh Kodam Jaya.

Pada penelitian ini subjek-nya adalah generasi milenial, penulis memilih generasi milenial yang spesifik yaitu mahasiswa yang pernah mengikuti pemberian materi yang disampaikan oleh Kapendam Jaya / Jayakarta, penulis memilih subjek tersebut karena selain penulis ingin mengetahui opini publik dari generasi milenial sesuai dengan tema penelitian penulis. Dengan objek penelitian yang dipilih oleh penulis ialah kredibilitas komunikator dalam menyampaikan informasi, secara spesifik kredibilitas komunikator Kapendam Jaya / Jayakarta yang dapat dinilai dari kompetensi, sikap, niat, kepribadian dan dinamisme.Pengumpulan data yang dilakukan oleh peneliti menggunakan survei dengan kuesioner sebagai alat bantu yang digunakan oleh peneliti.

\section{Hasil Temuan dan Diskusi}

Kegiatan kuesioner dilakukan secara elektronik, dengan aplikasi Google Form. Kuesioner ini diikuti oleh mahasiswa dari tiga Universitas diantaranya 101 mahasiswa Universitas Tarumanagara, 46 mahasiswa Universitas Paramadina, dan 
20 mahasiswa Universitas Kristen Indonesia. Kuesioner ini bertujuan untuk mengukur Kredibilitas yang dimiliki oleh Kapendam Jaya / Jayakarta, dari opini audience.

Hasilnya secara umum diketahui bahwa kredibilitas yang dimiliki oleh Kapendam Jaya tersebut baik, hal tersebut terbukti dari empat belas pernyataan mengenai kredibilitas Kapendam Jaya / Jayakarta, dan satu buah pernyataan mengenai yang paling diingat dari sosok Kapendam Jaya / Jayakarta. Dengan hasil yang paling dingat dari ketiga universitas tersebut pada posisi pertama ialah seragam yang dikenakan oleh Kapendam Jaya / Jayakarta, pada posisi kedua yang paling diingat adalah sikap gagah yang dibawakan oleh Kapendam saat membawakan materi, dan pada posisi ketiga responden Universitas Tarumanagara dan Universitas Paramadina memilih materi, bertolak belakang dengan hasil tersebut responden Universitas Kristen Indonesia memilih bahasa dan kewibawaan yang dimiliki oleh Kapendam Jaya / Jayakarta sehingga pada posisi ke-tiga seimbang.

Gambar 1. Presentase yang paling diingat dari Kapendam Jaya / Jayakarta
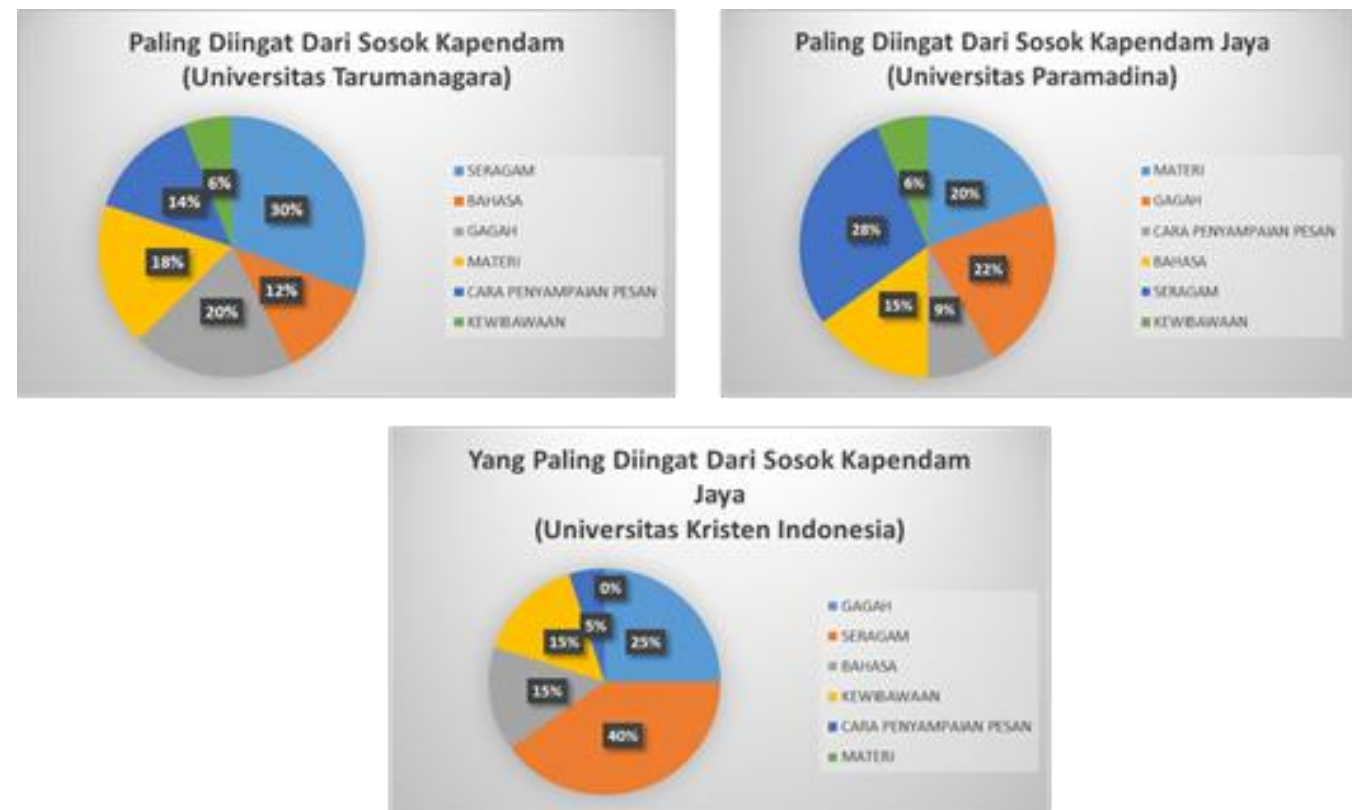

Sumber: Olahan Data Penulis (2018)

Dalam wawancara yang dilakukan oleh Kapendam Jaya / Jayakarta, beliau selalu menekankan pentingnya mengetahui latar belakang dari audience-nya.

"Nah. Supaya audience paham apa yang saya sampaikan saya harus tau latar belakang dari audience saya. Agar nantinya saya pun juga mudah dalam memberikan contoh, saya juga harus melakukan metode pendekatan misalkan audience saya seperti kamu ini mahasiswa. Kamu suka BTS atau Blackpink dan sejenisnya kan. Nah saya bisa melakukan pendekatan dari situ. Bahkan ada yang bilang tentara tapi suka Korea juga." (Kapendam Jaya / Jayakarta dalam wawancara Oktober 2018)

Hal tersebut selalu ditekankan agar Kapendam Jaya / Jayakarta tersebut agar dapat mencocokan materi yang akan dibawakan kepada audience-nya, menyesuaikan 
penampilan yang akan beliau bawakan, contoh yang akan dibawakan, ice breaking, literatur dan informasi terbaru yang nantinya akan dibawakan oleh Kapendam.

Kapendam Jaya / Jayakarta sering memberikan materi pembekalan dengan topik yang beragam beberapa topik terebut diantara lainnya: proxy war, hoax, nasionalisme, yang khususnya ditunjukan untuk generasi milenial karena generasi inilah yang beberapa tahun mendatang akan menjadi penerus bangsa Indonesia.

"Informasi yang saya sampaikan biasanya seputar sekarang ini hoax, rasa nasionalisme, kemudian pembelajaran mengenai proxy war. Mahasiswa seperti kamu dianggap seperti sudah dewasa dan sudah matang bisa membedakan mana yang bohongan mana yang real, apalagi kamu mahasiswa komunikasijadi diharapkan sudah lebih tahu. Saya berharapnya mahasiswa bisa membantu untuk tidak menyebarkan berita informasi yang gak bener, karena kan juga akan merugikan sesama." (Kapendam Jaya / Jayakarta).

Kapendam Jaya / Jayakarta merasa sangat percaya diri ketika datang membawakan informasi di universitas, atau sekolah-sekolah dengan menggunakan seragam TNI- Angkatan Darat, karena Kapendam merasa jika menggunakan seragam kredibilitasnya naik menjadi diatas $80 \%$, audience yang melihatnya pun juga langsung mempercayai jika Kapendam merupakan seorang tentara.

"Kredibilitas, kalau misalkan saya berbicara kepada kalian, oh bapak itu bekerja sebagai tentara, sudah begitu saja. Oke makanya setiap saya ke kampus untuk memberikan materi, contohnya di kampus kamu kemarin saya menggunakan seragam. Kalau saya menggunakan batik kamu pasti tidak akan percaya kalau saya seorang tentara. Oh bapak tentara itu bisa dipercaya, karena dalam benak saya jika saya menggunakan seragam saya bisa meng-grab kepercayaan kalian diatas 80\%, karena sejujurnya buang waktu banyak untuk perkenalan. Kalau saya pakai seragam sudah beda ceritanya pada intinya saya sudah menanamkan kepercayaan kepada kamu. Saya gak pernah kuliah di Untar, ya kita sama - sama, kalo saya pake seragam kan kamu tau saya dari luar saja ibarat bawang kulitnya kamu tau." (Kapendam Jaya / Jayakarta)

\section{Retrorika}

Aristoteles yang dikutip dari buku West dan Turner (2013) membagi dua asumsi mengenai retorika, asumsi pertama pembicara yang efektif harus mempertimbangkan khalayak mereka. Para pembicara tidak boleh menyusun tanpa mempertimbangkan khalayak mereka. Asumsi kedua, pembicara yang efektif menggunakan beberapa bukti dalam presentasi mereka. Bukti yang dimaksud oleh Aristoteles adalah ethos, logos dan pathos. Ethos adalah karakter, intelegensi, dan niat baik yang dipresepsikan dari seorang pembicara. Logos adalah bukti logis, penggunaan pendapat dan bukti dalam pidato, dan pathos adalah yang terkait dengan emosi pendengar.

Retorika tersebut berhubungan langsung dengan penelitian penulis di sisi lain Kapendam juga mempengaruhi generasi milenial atau mahasiswa untuk tidak menyebarkan hoax, penggunaan internet yang sewajarnya, kemudian pada asumsi pertama, karena sebagai pembicara Kapendam Jaya selalu memperhatikan latar belakang audience-nya sebelum memberikan materi. Hal tersebutlah yang selalu ditekankan oleh Kapendam berkali-kali ketika melakukan wawancara dengan 
penulis. Sedangkan pada asumsi kedua Kapendam juga terdapat bukti seperti yang dimaksudkan, yaitu ethos, pathos dan logos. Pada bagian ethos terlihat dari hasil kuesioner, audience dari ketiga universitas setuju dengan materi yang dibawakan oleh Kapendam sesuai dengan tema nya. Logos, adanya bukti foto humanis yang ditampilkan ketika membawakan materi di Universitas Tarumanagara. Terbukti juga dengan hasil wawancara yang dilakukan oleh penulis beberapa waktu lalu terkait dengan foto tentara Israel yang dikiranya akan dibunuh oleh tentara Amerika.

"Kalau untuk contoh saya sebebernya bisa ambil dari mana aja lingkungan sekitar, atau berita-berita yang lagi booming sekarang. Balik lagi saya pun harus melihat siapa audience-nya saya. Kalau mahasiswa ya saya harus sesuaikan, kalo kamu masih ingat isi presentasi saya yang saya menjadi dosen tamu kemarin. Itu ada foto tentara Israel yang dikiranya akan dibunuh oleh tentara Amerika kan. Tapi coba kamu lihat gambarnya jangan setengah, pasti berbeda kan, nah itu yang saya maksud contohnya. Apalagi kamu mahasiswa komunikasi melihat jangan dari satu arah saja. Lihatlah dari pandangan yang berbeda juga." (Kapendam Jaya / Jayakarta)

\section{Kredibilitas Komunikator}

Terdapat tiga macam kredibilitas yang dibagi oleh Mulyana, yaitu kredibilitas sumber McCroskey yang dikutip dalam Mulyana (2008) mengemukakan dimensi pertama kredibilitas sumber keotoritatifan atau keahlian menunjukkan bagaimana pembicara dipersepsi berkenaan dengan subjek yang disajikan bagaimana pendapat kita mengenai kecerdasan pembicara, informasi yang dimilikinya, kompetensi, dan kewibawaannya, dimensi kedua karakter atau watak dipersepsi sehubungan dengan maksud dan tujuannya - apakah pembicara terlihat objektif, dapat diandalkan, bermotivasi baik, dan disukai. Dimensi yang terakhir adalah kedinamisan yaitu, bagaimana kemampuannya dalam membujuk, keaktifan dan semangatnya menjadi pembicara. Kredibilitas berikutnya, yaitu ekstrinsik adalah kredibilitas yang dianggap memiliki sumber sebelum dia menyampaikan pesannya. Diantaranya adalah keahlian, status, kepandaian, yang dipersepsi berdasarkan sumber, keterpercayaan sebagai keberpihakan (objektivitas), dan ketiadaan maksud untuk membujuk yang dipersepsi (McGuirce dalam Mulyana 2008). Kredibilitas terakhir adalah intrinsik adalah istilah yang sering diberikan kepada citra yang diciptakan oleh sebagai hasil langsung pidatonya. Intrinsic ethos dibentuk oleh topik yang dipilih, cara penyampaian, teknik pengembangan pokok bahasan, dan bahasa yang dipergunakan, serta organisasi atau sistematika yang dipakai (Rackmat, 2011).

Dalam dimensi sumber terdapat pecahan dua dimensi lainnya, diantaranya ada dalam diri Kapendam Jaya/Jayakarta. Seperti dimensi keahlian, terpancar dari cara Kapendam dalam kecerdasan dalam komunikator menyampaikan informasi kepada audience-nya, sejauh mana pemahaman audience terhadap apa yang disampaikan oleh komunikatornya, penguasaan materi yang dibawakan oleh komunikator. Dalam dimensi pertama ini dapat dikatakan jika audience menilai komunikator dalam menyampaikan pesan. Dimensi kedua atau dimensi ke dinamisan berkaitan dengan karakter dari komunikator tersebut, karakter dapat terpancar dari cara pembawaan komunikator dalam membawakan pesan, karakter tersebut juga termasuk kedalam sifat kewibawaan, tegas yang dimiliki oleh Kapendam Jaya/Jayakarta. Dalam pemahamannya penulis, memahami dimensi sumber sebagai dimensi komunikator 
yang ada sebelum, komunikator tersebut membawakan pesan kepada audience-nya atau penilaian kepada komunikator.

Hampir sama dengan kredibilitas sebelumnya, kredibilitas ekstrinsik adanya kesan awal komunikator yang berpengaruh terhadap audience-nya. Kesan awal tersebut tentang penampilan dinamis pada penyampaian pesan Kapendam Jaya. Kredibilitas ekstrinsik ini juga memandang semakin tinggi jabatan yang dipangku oleh seseorang maka akan dipercaya, sama halnya dengan Kapendam Jaya / Jayakarta mahasiswa melihat Kapendam Jaya sebagai tentara, tetapi tidak tahu menduduki jabatan apa, tetapi setelah diperkenalkan mahasiswa menjadi tahu akan jabatan Kapendam Jaya tersebut. Hal tersebut berarti adanya keterpercayaan yang ada dalam kredibilitas ini, hal tersebut menambah pengaruh persuasif secara tidak langsung kepada audience.

Kredibilitas intrinsik didapatkan ketika Kapendam sebagai hasil yang dinilai dari audience kepada Kapendam. Hasil tersebut ada ketika Kapendam telah menyelesaikan materinya. Salah satunya adalah cara penyampaian Kapendam Jaya / Jayakarta, audience menilai cara penyampaian sesuai dengan tema yang dibawakannya, adanya variabel hiburan atau ice breaking, variabel hiburan tersebut menguncang gelak tawa dari audience yang memperhatikan Kapendam. Hal tersbut terlihat dalam penyampaian informasinya agar tidak terlalu membosankan sehingga ada warna atmotsfer, menciptakan suasana agar tidak terlalu menegangkan juga.

"Pasti pakai untuk mencairkan suasana dan membawa lebih hidup, kembali lagi harus tau siapa audience-nya. Gak mungkin kan saya memberikan humor ke kalian tentang ketentaraan. Pasti kan kalian juga bingung bantem apa (bantuan tembakan), pastimaterinya saya sesuaikan juga dengan audience-nya. Ya contohnya sebenernya saya juga suka korea kayak BTS sama Blackpink anak - anak kayak kamu kan tau, nah itu pun bisa saya jadiin ice breaking." (Kapendam Jaya / Jayakarta)

\section{Simpulan}

Berdasarkan hasil penelitian yang telah dilakukan oleh penulis dengan menyebarkan kuesioner kepada 150 responden, yang memiliki kriteria responden telah mengikuti seminar atau dengan pembicara Kapendam Jaya. Penulis menyimpulkan bahwa ketiga dimensi kredibilitas seperti sumber, ekstrinsik, dan intrinsik ada pada diri Kapendam Jaya sebagai komunikator, sehingga penulis menyimpulkan opini publik yang didapatkan oleh Kapendam Jaya baik, karena telah mempengaruhi mayoritas responden. Kemudian penampilan seperti, apa yang dikenakan (seragam) merupakan salah satu komunikasi non verbal atau artifaktual, karena secara tidak langsung adanya ingatan dalam benak diri masing-masing audience. Penulis juga menyimpulkan Kapendam Jaya menggunakan acara baru untuk mendekati generasi muda, secara tidak langsung, hal tersebut mengubah pandangan generasi milenial terhadap image TNI.

\section{Ucapan Terima Kasih}

Ucapan terimakasih diberikan kepada Fakultas Ilmu Komunikasi Universitas Tarumanagara, pembimbing Sinta Paramita, S.I.P., M.A dan juga kepada narasumber Kolonel Inf. Kristomei Sianturi, yang telah membantu sebagai narasumber, dan juga kepada semua pihak yang turut mendukung, dan membantu penelitian ini. 


\section{Daftar Pustaka}

Brawijaya. (2014). Tugas Pokok Pendam. 22 Januari <http://www.kodam5brawijaya.mil.id/berita/detail/567/tugas-pokok-pendam.html>, diunduh tanggal 19 September 2018

Candraningrum, D. (2018). Teknologi Komunikasi Informasi Untuk Peningkatan Kesadaran Publik Pada Organisasi Sosial. Jurnal Komunikasi, 10(2), 177-185.

Creswell, Jhon W. (2016). Research Design Pendekatan Kualitatif, Kuantitatif, dan Mixed. Yogyakarta: Pustaka Pelajar.

Dimyanti. (2016). Menjaga Kredibilitas TNI di Mata Publik. 29 Maret 2016 <https://tni.mil.id/view-94026-menjaga-kredibilitas-tni-di-mata-publik.html>, diunduh tanggal 19 Agustus 2018

Fitryarini, I. (2017). Literasi Media Pada Mahasiswa Prodi Ilmu Komunikasi Universitas Mulawarman. Jurnal Komunikasi, 8(1), 51-67. Retrieved from https://journal.untar.ac.id/index.php/komunikasi/article/view/46/52

Hendro. (2018). Aster Panglima TNI: Generasi Muda Indonesia Perlu Miliki Mental Ideologi. $22 \quad$ November $2018 \quad<$ http://indonews.id/artikel/17452/AsterPanglima-TNI-Generasi-Muda-Indonesia-Perlu-Miliki-Mental-Ideologi/>, Diunduh tanggal 1 Desember 2018

Mulyana, Deddy. (2008). Ilmu Komunikasi: Suatu Pengantar. Bandung: Remaja Rosdakarya.

Munazir, Aziz. (2018). Demi Semangat Kebhinekaan Generasi Millenial. 10 Maret $<$ https://nasional.kompas.com/read/2018/03/10/21305651/demi-semangatkebhinekaan-generasi-millenial> diunduh tanggal 19 September 2018

Olli, H., \& Novi Erlita. (2011) Opini Publik. PT Indeks, Jakarta.

Priyasmoro, M. R. (2018). Survei: TNI Lembaga Paling Dipercaya Masyarakat, Parpol Terendah: (2018, Agustus 28) <https://www.liputan6.com/news/read/3630486/survei-tni-lembaga-palingdipercaya-masyarakat-parpol-terendah> Diunduh tanggal 10 Desember 2018

Putra, Y. S. (2017). Theoritical review: Teori perbedaan generasi. Jurnal Ilmiah Among Makarti, 9(18)

Rumantini, Maria Assumpta. (2005). Dasar-Dasar Public Relations: Teori dan Praktek. Jakarta: PT. Gramedia Widiasarna Indonesia

Sugiyono. (2011). Metodelogi Penelitian Kuantitatif, Kualitatif Dan R\&D. Bandung: Alfabeta. 